\title{
Peran Paguyuban di Balikpapan dalam Mendukung Integrasi Sosial
}

\author{
Nawang Retno Dwiningrum ${ }^{1 *}$, Patria Rahmawaty ${ }^{2}$, Totok Ismawanto ${ }^{3}$ \\ ${ }^{1,2,3}$ Politeknik Negeri Balikpapan, Balikpapan \\ nawang.retno@poltekba.ac.id
}

\begin{abstract}
Ths study analyze the community's role in supporting social integration and to know what factors that support and inhibit. The research methodology that was used in this research was qualitative descriptive. The community's role to support social integration has been carried out by the community that can be seen in the activities that was coordinated by community in Balikpapan for the common interest of the community such as social activities, being part of the interfaith harmony organization, participating in the cultural parade that was celebrated by the municipality. While establishment of community forum, it can further consolidated unity among the community. Supporting factors, Balikpapan government very supported with the activities of the community, held gatherings between community that collect all of the association in Balikpapan 2-3 times a year and provided assistance for example in the form of consumption, the factors of social inhibition were limited funds to conducted this activities and if there was an organization of a particular ethnicity, intimidation of certain ethnicity will inhibited social integration.
\end{abstract}

Key words: role, community, social integration

\begin{abstract}
Abstrak
Tujuan penelitian ini adalah untuk mendiskripsikan dan menganalisis peran paguyuban dalam mendukung integrasi sosial dan untuk mengetahui faktor-faktor apa yang mendukung dan menghambat. Jenis penelitian yang dilakukan termasuk penelitian deskriptif kualitatif. Peran paguyuban untuk mendukung integrasi sosial sudah dilaksanakan oleh paguyuban terlihat dalam kegiatan-kegiatan yang dilakukan oleh paguyuban yang ada di Balikpapan untuk kepentingan bersama masyarakat seperti kegiatan sosial, menjadi bagian dalam organisasi kerukunan antar umat beragama, ikut dalam pawai budaya yang dilakukan oleh pemerintah kota. Dengan dibentuknya Forum Paguyuban lebih memperkuat persatuan antar paguyuban. Faktor pendukung, pemerintah Kota Balikpapan sangat mendukung kegiatan paguyuban diadakan silaturahmi antar paguyuban yang mengumpulkan paguyuban seluruh Balikpapan 2-3 kali setahun dan memberikan bantuan misalnya dalam bentuk konsumnsi, faktor penghambat integrasi sosial adalah keterbatasan dana untuk melakukan kegiatan dan apabila ada arogansi dari etnis tertentu, intimidasi dari etnis tertentu akan menghambat integrasi sosial.
\end{abstract}

Kata Kunci: peran, paguyuban, integrasi sosial

\section{Pendahuluan}

Indonesia terdiri dari berbagai

macam suku, agama dan ras atau sering disebut sebagai masyarakat yang majemuk. Indonesia adalah bangsa yang majemuk. Menurut Clifford Geertz) (Depdikbud, 2012:180) masyarakat Indonesia adalah masyarakat majemuk, adalah merupakan masyarakat yang terbagi-bagi ke dalam subsub sistem yang kurang lebih berdiri sendirisendiri dalam mana masing-masing sub sistem terikat ke dalam oleh ikatan-ikatan yang bersifat primordial.

Menurut Nasikun (1998) Struktur masyarakat Indonesia ditandai oleh dua cirinya yang unik. Secara horisontal 
JURNAL SOSIAL HUMANIORA DAN PENDIDIKAN VOL. 2 NO. 1

masyarakat Indonesia oleh kenyataan adanya

kesatuan-kesatuan sosial berdasarkan

perbedaan-perbedaan suku bangsa,

perbedaan agama, adat, serta perbedaan-

perbedaan kedaerahan. Secara vertikal

struktur masyarakat Indonesia ditandai oleh

adanya perbedaan-perbedaan vertikal antara

lapisan atas dan lapisan bawah yang cukup tajam.

Balikpapan adalah suatu kota yang terdiri dari berbagai macam suku, agama, etnik yang merupakan cerminan dari Indonesia yang majemuk. Secara garis besar ada lima budaya dasar suku bangsa asal Kalimantan yang disebut Rumpun Kalimantan, empat di antaranya terdapat di Kalimantan Timur, khususnya Balikpapan yaitu: Banjar, Kutai, Dayak, Paser. Kemudian karena kemajuan kota Balikpapan sehingga banyak pendatang yaitu antara lain dari Jawa, Sulawesi, Madura.

Balikpapan sebagai pintu gerbang Kalimantan Timur letaknya sangat strategis dan mempunyai fasilitas Bandara, pelabuhan dan merupakan kota transit dan dilihat dari perkembangan kota Balikpapan lebih maju dibandingkan dengan kota atau kabupaten lain di Kalimantan Timur, sehingga tidak mengherankan banyak pendatang ke Balikpapan.

Berdasarkan asalnya, pendatang berasal dari pulau-pulau di sekitar seperti
Jawa, Madura dan Sulawesi. Jumlah pendatang paling banyak berasal dari Jawa yakni sebanyak 30\%, kemudian diikuti dengan Banjar dan Bugis masing-masing sebanyak 20\%, Toraja sebanyak $11 \%$, Madura sebanyak 8\%, Buton sebanyak $7 \%$ dan Betawi sebanyak 4\%. Tingkat pendidikan pendatang didominasi oleh lulusan SLTA sebanyak 36\%, diikuti lulusan SD sebanyak $25 \%$, tidak tamat SD sebanyak $23 \%$, lulusan SMP sebanyak $12 \%$ dan perguruan tinggi hanya 4\%. Alasan pendatang masuk ke Balikpapan beragam, paling banyak karena mencari pekerjaan (48\%), kemudian karena pindah kerja (33\%) dan karena ikut keluarga atau suami sebanyak

Sampai dengan bulan Januari 2015 jumlah penduduk di kota Balikpapan mencapai 706.414 Jiwa yang tersebar di 6 kecamatan, dan kecamatan dengan kepadatan penduduk tertinggi adalah kecamatan Balikpapan Utara. Pembangunan pesat dan peluang ekonomi yang tinggi mengundang arus pendatang yang cukup besar. Pada tahun 2014 laju pertumbuhan penduduk di kota Balikpapan mencapai 5,01\% atau bertambah sebesar 36.301 Jiwa, dengan kepadatan penduduk mencapai 1.380 jiwa/KM2 (BPS, 2016).

Besarnya jumlah pendatang di Kota Balikpapan telah membawa keberagaman 
etnis, sehingga Balikpapan dikenal sebagai

kota yang heterogen, baik dari segi adat istiadat maupun agama. Namun demikian hal ini tidak menjadi kendala dalam mewujudkan keharmonisan dalam kehidupan bermasyarakat. Tercatat setidaknya 109 kelompok etnis/paguyuban yang ada di Balikpapan. Paguyuban ini berperan penting dalam menjaga keharmonisan masyarakat, sehingga Balikpapan menjadi salah satu kota yang tidak pernah terjadi konflik dan aman dari kerusuhan suku, agama dan ras.

Penelitian yang terdahulu yang meneliti tentang paguyuban adalah penelitian Zessy Ardinal Barlan (2014:131). Peran Paguyuban dalam pembangunan kawasan desa. Hasil penelitian menunjukkan Paguyuban di Balikpapan berperan dalam pembangunan kawasan Karang juang melalui sosialisasi dan pola-pola hubungan etnisitas melalui elit-elitnya mengutamakan hubungan etnisnya dalam pembangunan kawasan.

Berbeda dengan penelitian terdahulu focus penelitian ini adalah peran paguyuban dalam mendukung integrasi sosial . berdasarkan latar belakang tersebut maka peneliti merumuskan judul penelitian adalah : Peran Paguyuban dalam Integrasi Sosial (Studi Kasus di Kota Balikpapan).

\section{Metodologi}

$$
\text { Jenis penelitian yang dilakukan }
$$

termasuk penelitian deskriptif kualitatif. Menurut Nasution (1989: 39), dimana metode deskriptif dapat diartikan sebagai prosedur pemecahan masalah yang diselidiki dengan menggambarkan atau melukiskan keadaan subyek atau obyek penelitian seseorang, lembaga, masyarakat dan lainlain pada saat sekarang berdasarkan faktafakta yang tampak atau sebagaimana adanya. Untuk mendapatkan gambaran yang lebih mendalam penelitian tersebut akan dianalisis secara kualitatif.

\section{Hasil dan Pembahasan}

Ada 109 paguyuban yang ada di Balikpapan, paguyuban ini bersifat kedaerahan yang mewakili 32 etnis di Kota Balikpapan. Kerukunan Keluarga Minahasa Selatan (KKMS) adalah salah satu paguyuban yang berdasarkan kedaerahan. Berdasarkan tujuan dibentuknya kkms ada tiga tujuan yaitu :

1. KKMS bertujuan untuk menghimpun segenap potensi masyarakat Balikpapan asal Minahasa Selatan, Sulawesi Utara yang berwawasan Nusantara, ahli, terampil, bertanggungjawab, jujur serta arif dan bijaksana untuk mengembangkan kehidupan sosial, pendidikan, hukum, seni, budaya dan pariwisata Balikpapan dan sekitarnya dengan semangat MAPALUS (KEBERSAMAAN) dalam rangka mewujudkan cita-cita perjuangan 
JURNAL SOSIAL HUMANIORA DAN PENDIDIKAN VOL. 2 NO. 1 pahlawan nasional Dr.G.S.S.J Ratulangi yakni Si Tou Timou Tumou Tou yang artinya "Manusia hidup untuk menghidupi sesama manusia”.

2. Membina dan mengembangkan kehidupan beragama yang sehat dan penuh toleransi demi terciptanya kerukunan antar umat beragama di kota Balikpapan dan sekitarnya, yang diyakini dapat meningkatkan rasa persatuan dan kesatuan dalam bernegara, berbangsa dan bermasyarakat demi kuat dan tegaknya Negara Kesatuan Republik Indonesia (NKRI).

3. Berpartisipasi langsung dalam upaya mewujudkan tujuan nasional seperti yang tercantum dalam Pembukaan/ Mukadimah UUD 1945.

Berdasarkan uraian diatas walaupun paguyuban KKMS dibentuk berdasarkan ikatan kedaerahan, tetapi ada nilai-nilai kedaerahan seperti "mapalus” (kebersamaan) yang bisa diangkat menjadi semangat dalam mewujudkan persatuan dan kesatuan, dan tujuan dibentuknya Kerukunan Keluarga Minahasa Selatan seperti tercantum diatas dapat diambil kesimpulan jika pembentukan KKMS mendukung terwujudnya kerukunan antar umat beragama, persatuan dan kesatuan bernegara dengan kata lain KKMS berperan serta dalam mewujudkan integrasi sosial .
ISSN $2580-5398$

Kerukunan Keluarga Minahasa

Selatan dan tercatat sebagai anggota Forum Komunikasi Paguyuban Balikpapan (FKPB) di kota Balikpapan.

Begitu juga visi misi dari paguyuban Bali dengan Visi untuk mewujudkan masyarakat Hindu Dharma yang sejahtera dan bahagia. Sedangkan misinya adalah meningkatkan perilaku yang memiliki etika dalam kehidupan beragama yang modern, meningkatkan kesadaran masyarakat untuk membangun sumber daya manusia yang maju, unggul, mandiri, berbudaya serta menumbuh kembangkan wawasan solidaritas, keharmonisan internal dan eksternal.

Menurut pengurus Paguyuban Bali, ada nilai yang diterapkan di paguyuban Bali : "Ada beberapa nilai-nilai yang diterapkan dalam paguyuban ini seperti saling menghormati, saling menghargai, saling membantu dan mendukung yang tujuannya untuk menciptakan kerukunan dan kebersamaan diantara anggota paguyuban" (Hasil wawancara, 29 Juli 2017 ).

Dan kegiatan-kegiatan yang dilakukan oleh Paguyuban Bali juga banyak melibatkan masyarakat umum : kerjabakti dengan masyarakat disekitar lingkungan pura, terlibat dalam pawai budaya yang dilakukan oleh pemerintah kota, membantu warga sekitar lingkungan yang sedang 
mengalami sengketa tanah, dan menjadi bagian dalam organisasi kerukunan antar umat beragama

Dari visi misi, nilai dan kegiatan yang diterapkan oleh Paguyuban Bali sangat mendukung proses integrasi sosial di Balikpapan IWSS - BERSATU memiliki tujuan menciptakan hubungan kekeluargaan dan mempersatukan seluruh wanita Sulawesi Selatan yang berdomisili di luar SulawesiSelatan atas dasar gotong royong serta musyawarah mufakat untuk meningkatkan partisipasi warganya dalam pembangunan Bangsa dan Negara.

Menurut Sekretaris umum Ikatan Wanita Sulawesi Selatan (IWSS) : "kegiatan yang dilakukan oleh Ikatan Wanita Sulawesi selatan (IWSS) sesuai program-program yang telah dilakukan yaitu Pagelaran Budaya , peduli narkoba , ceramah kesehatan kanker servic dan penanaman mangrove, Seminar Pola Asuh usia Dini, ikut serta dalam pawai budaya Balikpapan kegiatan sosial bantuan kepada korban kebakaran, bantuan kepada panti jompo dan anak yatim, kelas mengajar di SD, mengikuti Food and Culture Festival “. (Hasil wawancara, 8 Agustus 2017 ).

Berdasarkan kegiatan-kegiatan yang dilakukan oleh paguyuban yang ada di Balikpapan untuk kepentingan bersama masyarakat seperti kegiatan sosial, menjadi bagian dalam organisasi kerukunan antar umat beragama, ikut dalam pawai budaya yang dilakukan oleh pemerintah kota, kegiatan itu sangat mendukung integrasi sosial.

Peran Forum Komunikasi Paguyuban Balikpapan sangat mendukung dalam menangani konflik di masyarakat sehingga integrasi sosial di Balikpapan tetap terjaga. Menurut ketua Forum Komunikasi Paguyuban Balikpapan yang sekaligus juga merupakan Forum Kewaspadaan Dini Masyarakat Kota Balikpapan, apabila ada konflik maka saya akan turun ke lapangan dan berusaha untuk menyelesaikan.(Hasil wawancara, 7 Agustus 2017).

Jadi fungsi dari Forum Komunikasi Paguyuban Balikpapan sangat strategis terutama dalam membantu kepolisian menyelesaikan konflik-konflik dalam masyarakat. Untuk merekatkan antar paguyuban, semua paguyuban yang ada di Balikpapan dilibatkan dalam beberapa acara misalnya, pada acara pemberdayaan perempuan oleh kantor Kesbangpol banyak dilibatkan paguyuban dengan menampilkan seni budaya misal tarian daerah.

Seperti dikemukakan oleh Leo Sukoco selaku Ketua forum Komunikasi Paguyuban Balikpapan : "Peran serta paguyuban dalam memperingati hari kemerdekaan misalnya sekarang pada acara 
menjelang upacara kemerdekaan semua paguyuban harus mengirimkan 1 pasang untuk berpakaian daerah dan sudah ada 20 paguyuban yang sudah siap dan sudah hampir mewakili semua daerah yang ada di Indonesia dalam mengikuti upacara kemerdekaan" . (Hasil wawancara, 7 Agustus 2017).

Menurut Kasi Hubungan antar lembaga dan pembinaan politik pemkot Balikpapan Sebagai wadah paguyuban dibentuk Forum Komunikasi Paguyuban Balikpapan yang bisa memberikan rekomendasi untuk pendaftaran baru/ perpanjangan ormas kedaerahan.

Menurut Ketua Forum Komunikasi Paguyuban Balikpapan, tentang jumlah paguyuban di Balikpapan: "Di Balikpapan ada sekitar 32 etnis dan 109 paguyuban, peran paguyuban disini sangat menonjol terutama dalam hal pelestarian budaya, jadi di Balikpapan adalah wujud miniatur Indonesia yang beragam etnis dan budaya. Dan adanya proses kawin silang antar suku yang menumbuhkan integrasi di Indonesia." (Hasil wawancara, 7 Agustus 2017).

Menurut Ketua Forum Komunikasi Paguyuban Balikpapan, tujuan dibentuknya forum komunikasi Paguyuban Balikapapan "Tujuan dibentuknya Forum Komunikasi Paguyuban Balikpapan awalnya adalah terispirasi konflik Sampit dan Sambas sekitar tahun 1990an , pada awalnya ada 17 paguyuban yang tergabung dalam forum ini dan sampai sekarang sudah 109 paguyuban yang bergabung. Forum ini dibentuk agar ada komunikasi antar paguyuban”. (Hasil wawancara, 7 Agustus 2017) Jadi untuk untuk mendorong proses integrasi sosial dan mengurangi konflik di Balikpapan sudah terbentuk Forum Komunikasi Paguyuban Balikpapan, sebagai wadah komunikasi antar paguyuban.

Kegiatan-kegiatan yang sudah dilakukan oleh Forum Komunikasi Paguyuban Balikpapan antara lain seperti dikemukakan oleh Ketua Forum Komunikasi Paguyuban Balikpapan"Forum Komunikasi Paguyuban Balikpapan murni kegiatan sosial dalam 1 tahun ada 5 kegiatan seperti silaturahmi bulanan, pengajian, festival kuliner tradisional dan tari-tarian daerah. Rapat paguyuban dilakukan 1 bulan sekali, dan akan diadakan rapat darurat apabila ada konflik, yang sering terjadi konflik sosial". (Hasil wawancara, 7 Agustus 2017).

Dari kegiatan yang sudah dilakukan oleh Ketua Forum Komunikasi Paguyuban Balikpapan menunjukkan ada agenda rutin untuk komunikasi antar paguyuban yang bertujuan untuk mendukung integrasi sosial.

Kegiatan yang dilakukan oleh paguyuban ini murni kegiatan sosial 
terutama untuk mendukung pelestarian budaya daerah. Dikemukakan oleh Ketua Forum Komunikasi Paguyuban Balikpapan mengenai kegiatan yang ada di paguyuban yang terdiri dari berbagai macam etnis ini, tidak melupakan budaya dan memegang teguh budaya masing-masing daerah, bahkan semenjak tahun 1990 budaya daerah mulai dikembangkan di Balikpapan misalnya dalam hal acara penganten, arisan yang memakai pakaian dan kuliner daerah, hal ini tidak terlepas dari peran paguyuban, yang tujuannya melestarikan kebudayaan.

Hal yang sama dikemukakan oleh Kasi Hubungan antar lembaga dan pembinaan politik, Kantor Kesbangpol pemkot Balikpapan :“ Peran paguyuban ikut terlibat dalam kegiatan budaya dan seni misalnya Hari ulang tahun Balikpapan, Ulang tahun KODIM, menampilkan seni budaya masing masing daerah". (Hasil wawancara, 11 Juli 2017).

Walaupun Balikpapan tidak pernah ada konflik besar tetapi konflik-konflik kecil masih ada misalnya Tahun 2011 pernah terjadi konflik orang Bugis dan penduduk asli daerah dan konflik internal paguyuban.

Untuk penanganan konflik seperti dikemukakan Kantor Kesbangpol yang menyangkut antar etnis atau paguyuban prosedurnya adalah: Apabila ada konflik/ pelanggaran biasanya tidak ada laporan ke

kesbangpol tetapi ke kepolisian kemudian dirapatkan oleh pimpinan daerah bila ada bukti pelanggaran baru dipanggil oleh kesbangpol

\section{Faktor pendukung dan penghambat Peran paguyuban dalam mendukung integrasi sosial}

\section{Faktor pendukung}

Pemerintah Kota Balikpapan sangat mendukung kegiatan paguyuban dengan mengadakan yaitu diadakan silaturahmi antar paguyuban yang mengumpulkan paguyuban seluruh Balikpapan 2-3 kali setahun dan memberikan bantuan untuk kegiatan yang dilaksanakan.

\section{Faktor penghambat}

Faktor penghambat untuk melakukan kegiatan adalah keterbatasan dana baik untuk pengembangan ketrampilan maupun kegaitan sosial yang melibatkan masyarakat.

Banyak organisasi yang belum mempunyai akte notaris yang menyatakan pendirian /AD/ART, masih ada paguyuban yang belum mendaftar ke Kantor Kesbangpol sehingga sulit untuk memantaunya. Ada arogansi dari etnis tertentu, intimidasi dari etnis tertentu akan menghambat integrasi sosial.

\section{Kesimpulan}


Peran paguyuban dalam mendukung integrasi sosial terlihat dalam kegiatankegiatan yang dilakukan oleh paguyuban yang ada di Balikpapan untuk kepentingan bersama masyarakat seperti kegiatan sosial, menjadi bagian dalam organisasi kerukunan antar umat beragama, ikut dalam pawai budaya yang dilakukan oleh pemerintah kota. Dengan dibentuknya Forum Paguyuban lebih memperkuat persatuan antar paguyuban.

Faktor pendukung, pemerintah Kota Balikpapan sangat mendukung kegiatan paguyuban misalnya dengan silaturahmi antar paguyuban yang mengumpulkan paguyuban seluruh Balikpapan 2-3 kali setahun dan memberikan bantuan dana, faktor penghambat integrasi sosial adalah keterbatasan dana untuk melakukan kegiatan dan apabila ada arogansi dari etnis tertentu, intimidasi dari etnis tertentu akan menghambat integrasi sosial.

\section{Saran}

Perlu diadakan penelitian lebih lanjut tentang peran pemerintah daerah dalam pembinaan terhadap paguyuban.

\section{Ucapan Terima Kasih}

Terimakasih kami sampaikan kepada Bp Algazali selaku Kasi Hubungan antar lembaga dan pembinaan politik kantor Kesbangpol Balikpapan, Bp Leo Sukoco
Ketua Forum paguyuban Balikpapan, Bp Nengah Kayun selaku pengurus Paguyuban Bali, ibu Nurwahidah jamal selalu sekretaris Ikatan Wanita Sulawesi Selatan, dan pengurus paguyuban di Balikpapan.

\section{Daftar Pustaka}

Ardinal Barlan , Zessy; M.Kolopaking, Lala. 2014. Peran Paguyuban dalam Pembangunan Kawasan Desa. Jurnal Sodality Sosiologi Pedesaan Vol 8 No 2 .

BPS. 2016. Kota Balikpapan dalam Angka. Balikpapan

Depdikbud, 2012, Buku Modul Kuliah Kewarganegaraan, Jakarta. Depdikbud

Nasikun. 1988. Sistem Sosial Indonesia. Jakarta: Rajawali Perss

Nasution. 1988. Metode Naturalisitik Kualitatif. Bandung:Tarsito 